\title{
Derivation and basic characterization of colorectal carcinoma primary cell lines
}

\author{
Lukas Krbala , Jiri Soukupa ${ }^{a}$, Stanislav John ${ }^{\mathrm{b}, c}$, Veronika Hanusova ${ }^{\mathrm{b}}$
}

Background. Colorectal carcinoma is one of the most common malignancies in western countries. Among different approaches to its research, primary cancer cell lines can play an important role.

Aim. The main purposes of this study were: 1) to establish an effective and reproducible method of colorectal cancer cell isolation and cultivation from primary tumours and lymph node metastases and 2) to elucidate the biological features of the tumours favouring successful cell cultivation.

Materials and Methods. The tumour cells were obtained from colectomy specimens. Primary tumour and lymph node metastasis tissue was used for establishing the tissue cultures. Colectomy samples were further processed for routine histopathological assessment: tumour grade, stage, angioinvasion and perineural spread were evaluated. Features of tissue culture cells were assessed using phase contrast microscopy and immune-histochemical techniques. WST1 assay and X-CELLigence real time analysis were carried out for viability and proliferation testing before and after treatment with irinotecan and oxaliplatin. Molecular features of the tumour including K-RAS/B-RAF/N-RAS mutations were tested using allele-specific PCR. Results of the cultivation process were compared to the histopathological and molecular features of the tumours.

Results. In total, we obtained 33 samples from the primary site of tumours and 20 samples from lymph node metastases; in total, 27 cell lines were successfully isolated. Morphologic features characteristic of tumour cells in primary cell lines and epithelial differentiation (positive for AE1/AE3 cytokeratin) were evaluated. Higher tumour stage, angioinvasion and presence of perineural spread in primary tumour correlated positively with successful cell isolation from lymph node metastasis. All samples tested were NRAS wild-type. No correlation was found between molecular phenotype and the cell culture features. A higher proliferation potential was observed in the primary tumour cells, whereas higher sensitivity to irinotecan was found in the lymph node metastatic cells.

Conclusions. Using mechanical dissociation, we successfully derived and cultivated CRC cells from primary tumours and lymph node metastases with success rate $3 \%$ and $70 \%$ respectively. Primary tumour features favouring successful establishment of cell cultures were identified.

Key words: primary cancer cell line, colon, lymph node, characterization

Received: April 7, 2017; Accepted with revision: September 12, 2017; Available online: October 17, 2017

https://doi.org/10.5507/bp.2017.040

aThe Fingerland Department of Pathology, University Hospital Hradec Kralove and Faculty of Medicine in Hradec Kralove, Charles University, Hradec Kralove, Czech Republic

${ }^{b}$ Department of Medical Biology and Genetics, Faculty of Medicine in Hradec Kralove, Charles University, Hradec Kralove, Czech Republic 'Department of Oncology and Radiotherapy, University Hospital Hradec Kralove and Faculty of Medicine in Hradec Kralove, Charles University, Hradec Kralove, Czech Republic

Corresponding author: Veronika Hanusova, e-mail: hanusovav@lfhk.cuni.cz

\section{INTRODUCTION}

Colorectal cancer is one of the leading causes of cancer related morbidity and mortality, especially in western countries $^{1}$, with the Czech Republic represented prominently in the statistics. Despite slower rise of incidence in last years, however colorectal cancer-related mortality remains steady².

Progress in the development of new molecular techniques aids the intensification of efforts to personalise the treatment of colorectal cancer. One of these new therapeutic modalities is intended to target the signaling through an activated EGFR pathway. Molecular testing for genetic alterations of the EGFR signalling pathway has proved to be important in balancing cost-benefit ratios of treatment. Despite advances in the field of anticancer drugs and targeted therapy during the last two decades, a deeper understanding of cancer development, progression and metastasis as well as its interactions with the tumour microenvironment is needed. For these reasons, use of primary cell lines of colorectal cancer patients remain an invaluable tool ${ }^{3}$. Some problems must be addressed for a successful cultivation, including large amounts of intestinal bacteria and fungi present almost invariably in the tumour samples and intimate admixture of connective tissue and inflammatory infiltrate cells along with cancer cells. Thus, several procedures exist for selective isolation of neoplastic cells from the sample, such as the use of magnetic beads or cell sorting by FACS. However, the co-cultivation of both type of cells together can brings important additional information about in vitro interactions of tumour and its supporting stroma ${ }^{4}$.

Nowadays the application of molecular biology techniques for the study and characterization of genetic and 
epigenetic changes in the cells can be used for prognostic and predictive purposes in the continuing attempts to individualize therapy.

Tumour acquisition is the first step of this process. Priority should always be given to a proper histopathological assessment instead of merely obtaining tumour samples for research purposes. Parts of the tumour are selected with maximal effort to avoid areas of necrosis, followed by the cell dissociation procedure ${ }^{5}$.

There are several methods of cultivation of primary cell lines; ranging from simple to more sophisticated methods attempting to maintain more of the original architecture of the tissue. All of these procedures entail particular advantages and disadvantages, with none of the method guaranteeing successful and reproducible primary tumour cell cultivation ${ }^{3,6}$.

During preparation, it is highly desirable to maintain the original features and behaviour of the primary cancer cells. Poor choice regarding methodology, microbial contamination or inappropriate cultivation conditions can cause a change in the phenotype within the culture, genetic drift or crucial differences in the behaviour of cells in vitro compared to in vivo ${ }^{3,6}$.

The present study describes an easy method suitable for the isolation of colon cancer cells from the primary tumours and its lymph node metastases. In addition, histological characterization of tumour and the anti-proliferative effect of two chemotherapeutics were assessed.

\section{METHODS}

\section{Clinical samples}

All clinical samples were obtained from patients, who underwent surgery for colorectal carcinoma at the University Hospital in Hradec Králové. The study was approved by the local ethics committee (Reference number: 201206 S52P - attached as Supplementary file) and patients gave their written consent. Subjects with various staging and grading of the disease were included in the study. In total, 27 clinical samples of varying size and quality were obtained surgically from 35 patients.

\section{KRAS, NRAS, BRAF and PTEN Mutational Analysis}

DNA was extracted from formalin-fixed, paraffin embedded tumour tissue after deparaffinization in xylene and rehydration in ethanol using the commercial DNA Sample Preparation Kit (Roche, Basel, Switzerland) according to the manufacturer's protocol. Mutation analysis was performed by Massively Parallel Sequencing (NGS). Indexed Illumina NGS library was constructed from 100 ng tumour cell line DNA using KAPA Library Preparation Hyper Plus Kit (Kapa Biosystems). Hybrid selection was performed with a custom SeqCap EZ Choice Library (Roche NimbleGen). The library was designed using the genome build hg19 NCBI Build 37.1/GRCh37 (input genomic regions: $K R A S$ NM_004985.4 - full coding regions; NRAS NM_002524.4 - full coding regions; $B R A F$ NM_004333.4 - exons 11 a 15; PTEN NM_000314.4 - full coding regions). Paired-end cluster generation and sequencing were performed according to standard protocols from Illumina, using v2 kits. Sequencing data analysis and variant annotation was performed using NextGENe software (Softgenetics) with minimum $5 \%$ variant allele frequency filtering.

\section{Media}

Transport medium for tumours: PBS 10x, aqua pro injectione, Penicillin/Streptomycin (100U/mL, Gibco, Invitrogen), Amphotericin B (Sigma-Aldrich).

Washing medium: PBS 10x, aqua pro injectione, Penicillin/Streptomycin (100U/mL, Gibco, Invitrogen), Amphotericin B (Sigma-Aldrich).

Cultivation medium: RPMI 1640 medium (SigmaAldrich), Penicillin/Streptomycin (100U/mL, Gibco, Invitrogen), $15 \%$ foetal bovine serum (Gibco), insulin (100 IU/mL, Eli Lilly Czech republic), transferrin (2mg/ mL, Sigma-Aldrich)

\section{Cell isolation from tumour samples}

Samples of tumour tissue obtained by surgery were cut into small pieces to prevent central necrosis of the tissue and transported in a $15 \mathrm{~mL}$ tube with transport medium at room temperature. The tissue in the transport medium was placed on a Petri dish and washed several times to remove erythrocytes. The sample in the Petri dish was cleansed from fat and necrotic tissue, mechanically disintegrated by scissors and scalpel, and then pressed through a strainer using a syringe. The cells were at that point collected with a Pasteur pipette, resuspended in cultivation medium and transported into cultivation flasks.

\section{Cultivation of the cells}

The cells were grown in T-25 $\mathrm{cm}^{2}$ or T-75 $\mathrm{cm}^{2}$ culture flasks in a humidified atmosphere containing $5 \% \mathrm{CO}_{2}$ at $37^{\circ} \mathrm{C}$. The cells were usually observed $48 \mathrm{~h}$ post isolation and fresh medium was added. The cells were grown for two weeks after isolation in original cultivation medium, and fresh medium was added every 3 days. After this, the medium was generally changed every 2-3 days until the cells migrated from the tissue fragments and created a monolayer on the bottom of the flask. The cells were then incubated in a trypsin/EDTA solution at $37^{\circ} \mathrm{C}$ for $10-20$ min or until the cells were visibly rounded and could be easily detached from the culture flask. RPMI/15\% FBS was added to inhibit the trypsin and the cells were centrifuged ( $5 \mathrm{~min}, 500 \mathrm{G}$ ) and washed using fresh cultivation medium.

\section{Freezing and thawing}

The cells in cultivation medium were centrifuged for 5 min at $500 \mathrm{G}$, the supernatant was removed and the cell pellet was mixed with $10 \%$ DMSO in foetal bovine serum to a final concentration $1 \times 10^{6}-2 \times 10^{6}$ cells $/ \mathrm{mL}$. The suspension was preserved in liquid nitrogen $\left(-180^{\circ} \mathrm{C}\right)$ for further analysis. The thawing procedure consisted of the retrieval of frozen samples from containers, rapid thawing in a water bath, mixing with cultivation medium, centrifu- 
gation for $5 \mathrm{~min}$ at $500 \mathrm{G}$ and transferring the samples into the cultivation flask. When a sufficient number of viable cells $(80 \%)$ were reached, chemosensitivity testing, cancer markers determination and immunohistochemical analyses were carried out as described below.

\section{Immunohistochemical examination}

$4 \mu \mathrm{m}$ thick sections were cut from paraffin blocks and mounted on positively-charged slides. The primary antibody against cocktail of cytokeratins (AE1/AE3 clone, 1:100 dilution, Dako, Glostrup, Denmark) was used. Antigen retrieval was performed in a water bath for 20 min at $97{ }^{\circ} \mathrm{C}$ at pH 6 (buffer S1700, Dako, Glostrup, Denmark). Endogenous peroxidase activity was inhibited by immersing the sections in 3\% hydrogen peroxide. After incubation with the antibody, the sections were subjected to the EnVision ${ }^{\mathrm{TM}}$ FLEX (Dako, Glostrup, Denmark) staining system. Finally, the slides were counterstained with haematoxylin.

\section{Test of impedance using x-CELLigence}

The system measures electrical impedance across interdigitated microelectrodes integrated at the bottom of tissue culture E-plates. The measurement of impedance provides quantitative information about the biological status of the cells, including cell number, viability and morphology. The relative change in the electrical impedance is displayed by the system as arbitrary units called the cell index. Ninety microliters of culture medium was added to each well and plates were inserted into the device for background measurement, subsequently, $100 \mu \mathrm{L}$ of cell suspension (containing 2000 cells) was added in quadruplicate to the appropriate wells. The plates were left in the incubator at $37^{\circ} \mathrm{C}$ for $30 \mathrm{~min}$, and then inserted into the device. In the first phase, impedance was measured (with increases corresponding to cell proliferation) every hour for $72 \mathrm{~h}$. Each sample was assayed in quadruplicate and two independent experiments were conducted. The results obtained were expressed as a percentage of untreated control.

\section{Cytotoxicity assay}

Cytotoxicity of the chemotherapeutics (irinotecan, oxaliplatin) in the colorectal carcinoma and lymph node metastatic primary cells was evaluated by WST-1, which is a colorimetric assay based on the cleavage of tetrazolium salt to coloured formazan by mitochondrial dehydrogenases in living cells. This assay quantifies cell proliferation and viability by measuring the activity of mitochondrial enzymes. The colorectal carcinoma cells were seeded in 96-well microtiter plates and exposed to the tested chemotherapeutics at various concentrations in RPMI medium for up to $30 \mathrm{~h}$. At the end of each interval, the cells were rinsed with PBS; $100 \mu \mathrm{L}$ of WST-1 solution (1:10 final dilution) was added and the cultures were further incubated for $2 \mathrm{~h}$. Absorbance was recorded at $450 \mathrm{~nm}$ with $650 \mathrm{~nm}$ of reference wavelength by a Tecan Infinite M200 spectrophotometer (Tecan, Switzerland).

\section{RESULTS}

In total, we obtained samples from 35 patients: 33 samples were from the primary site of the tumour and 20 samples from lymph node metastasis sites, with 22 cell lines were successfully isolated. Out of the primary

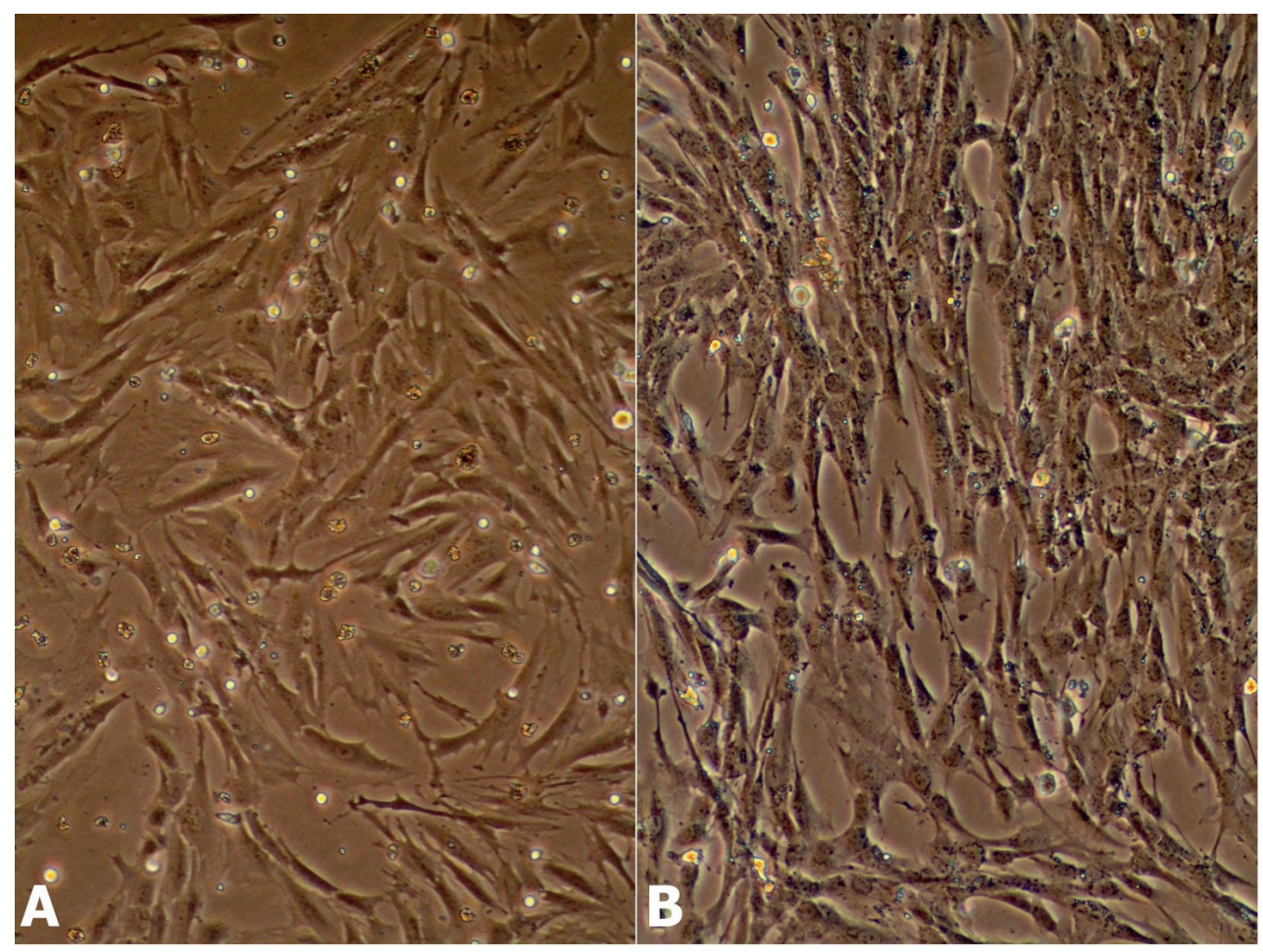

Fig. 1. Primary cell line of colorectal carcinoma derived from the tumour in gut $(\mathrm{A})$ and its respective lymph node metastasis (B) (200x, phase contrast). 
Table 1. Characteristics of primary colon cancer and respective lymph node metastasis according to the percentage of succesful isolation of corresponding cancer cells.

\begin{tabular}{|c|c|c|c|}
\hline & $\begin{array}{l}\text { Total No. } \\
(n=35)\end{array}$ & $\begin{array}{l}\% \text { of isolation } \\
\text { primary tumour }\end{array}$ & $\begin{array}{c}\% \text { of isolation } \\
\text { lymph node }\end{array}$ \\
\hline \multicolumn{4}{|c|}{ Stage of tumour } \\
\hline $\mathrm{T} 1$ & $1 / 35(3 \%)$ & $0 / 0(0 \%)$ & $1 / 1(100 \%)$ \\
\hline $\mathrm{T} 2$ & $5 / 35(14 \%)$ & $0 / 4(0 \%)$ & $1 / 3(33 \%)$ \\
\hline T3 & $23 / 35(66 \%)$ & $11 / 23(48 \%)$ & $8 / 12(66 \%)$ \\
\hline $\mathrm{T} 4 \mathrm{a}, \mathrm{b}$ & $6 / 35(17 \%)$ & $2 / 6(33 \%)$ & $4 / 4(100 \%)$ \\
\hline \multicolumn{4}{|c|}{ Stage of nodes } \\
\hline $\mathrm{N} 0+$ ITC & $18 / 35(51 \%)$ & $7 / 17(41 \%)$ & $4 / 7(57 \%)$ \\
\hline N1a, b & $11 / 35(31 \%)$ & $4 / 10(40 \%)$ & $6 / 8(75 \%)$ \\
\hline $\mathrm{N} 2 \mathrm{a}, \mathrm{b}$ & $6 / 35(17 \%)$ & $2 / 6(33 \%)$ & $4 / 5(80 \%)$ \\
\hline \multicolumn{4}{|c|}{ Tumour side } \\
\hline right & $15 / 35(43 \%)$ & $5 / 13(38 \%)$ & $7 / 9(78 \%)$ \\
\hline left & $20 / 35(57 \%)$ & $8 / 20(40 \%)$ & $7 / 11(64 \%)$ \\
\hline \multicolumn{4}{|c|}{ Tumour grading } \\
\hline G1 & $5 / 35(14 \%)$ & $2 / 4(50 \%)$ & $1 / 1(100 \%)$ \\
\hline G2 & $26 / 35(74 \%)$ & $8 / 25(32 \%)$ & $12 / 16(75 \%)$ \\
\hline $\mathrm{G} 3$ & $4 / 35(11 \%)$ & $3 / 4(75 \%)$ & $1 / 3(33 \%)$ \\
\hline \multicolumn{4}{|c|}{ Angioinvasion } \\
\hline positive & $14 / 35(40 \%)$ & $5 / 14(36 \%)$ & $5 / 6(83 \%)$ \\
\hline negative & $21 / 35(60 \%)$ & $8 / 19(50 \%)$ & $9 / 14(64 \%)$ \\
\hline \multicolumn{4}{|c|}{ Perineural spread } \\
\hline positive & $9 / 35(26 \%)$ & $2 / 9(22 \%)$ & $4 / 5(80 \%)$ \\
\hline negative & $26 / 35(74 \%)$ & $11 / 24(46 \%)$ & $10 / 15(67 \%)$ \\
\hline \multicolumn{4}{|c|}{ Mucinous component } \\
\hline positive & $7 / 35(20 \%)$ & $2 / 7(29 \%)$ & $1 / 2(50 \%)$ \\
\hline negative & $28 / 35(80 \%)$ & $11 / 26(42 \%)$ & $13 / 18(72 \%)$ \\
\hline
\end{tabular}

tumour samples (Fig. 1) we derived 13 primary cell lines with a success rate of $39.4 \%$ and from the lymph node metastasis samples (Fig. 1) we derived 14 primary cell lines with a success rate of $70 \%$.

The most effective isolation of cancer cells from primary colon tumours was observed in poorly differentiated tumours (grade 3 ) of advanced local stage (T3 stage of tumors) with success rate of $48 \%$ and $75 \%$ respectively. Tumours with histologically apparent angioinvasion or perineural spreading had a lower success rate of cell line isolation as did the tumours with a prominent mucinous component. The most successful isolation of cancer cells from lymph node was noted in specimens of high stage primaries (T4a, b; 100\%) and high stage nodal involvement (N2a, b; 80\%), as well as in tumours with angioinvasion $(83 \%)$ and perineural spreading $(80 \%)$ found upon histologic evaluation (Table 1).

Morphologic features characteristic of tumour cells in primary cell lines (Fig. 2A) and epithelial differentiation (positive AE1/AE3 cytokeratin stain - Fig. 2B) were evaluated and confirmed by a pathologist. The morphology of primary cell lines was compared with that of the respective primary tumor (Fig. 3A, 3B).

Pathological staging (TNM classification) of the primary tumours ${ }^{7}$ with a successful establishment of a primary cell line was following (Table 1).
Table 2. Molecular markers: $K R A S, N R A S$ mutation, $B R A F$ mutation and PTEN mutation in selected metastatic colon cancer patients.

\begin{tabular}{|c|c|}
\hline Molecular Markers & $\mathrm{n}(\%)$ \\
\hline \multicolumn{2}{|l|}{ KRAS mutations $(\mathrm{n}=15)$} \\
\hline positive & $10(67 \%)$ \\
\hline wild type & $5(33 \%)$ \\
\hline \multicolumn{2}{|c|}{ Specific $K R A S$ mutations $(\mathrm{n}=15)$} \\
\hline c. $35 \mathrm{G}>\mathrm{A}(\mathrm{p} . \mathrm{G} 13 \mathrm{D})$ & $1(7 \%)$ \\
\hline c. $35 \mathrm{G}>\mathrm{A}(\mathrm{p} . \mathrm{G} 12 \mathrm{D})$ & $3(20 \%)$ \\
\hline c. $35 \mathrm{G}>\mathrm{T}(\mathrm{p} . \mathrm{G} 12 \mathrm{~V})$ & $1(7 \%)$ \\
\hline c. $37 \mathrm{G}>\mathrm{T}(\mathrm{p} . \mathrm{G} 13 \mathrm{C})$ & $2(13 \%)$ \\
\hline c. $38 \mathrm{G}>\mathrm{A}(\mathrm{p} . \mathrm{G} 13 \mathrm{D})$ & $2(13 \%)$ \\
\hline c. $183 \mathrm{~A}>\mathrm{T}(\mathrm{p} . \mathrm{Q} 61 \mathrm{H})$ & $1(7 \%)$ \\
\hline wild type & $5(33 \%)$ \\
\hline \multicolumn{2}{|l|}{$N R A S$ mutations $(\mathrm{n}=15)$} \\
\hline wild type & $15(100 \%)$ \\
\hline \multicolumn{2}{|c|}{$B R A F$ c. $1799 \mathrm{~T}>A ; \mathrm{p} . \mathrm{V} 600 \mathrm{E}(\mathrm{n}=15)$} \\
\hline positive & $3(20 \%)$ \\
\hline wild type & $12(80 \%)$ \\
\hline \multicolumn{2}{|c|}{ PTEN c. $802-2 \mathrm{~A}>\mathrm{T}$, splice var. $(\mathrm{n}=15)$} \\
\hline positive & $1(7 \%)$ \\
\hline wild type & $14(93 \%)$ \\
\hline
\end{tabular}


The primary cell line from primary tumours (total $=13 / 33)$ : pT1 (involvement of mucosa) $=0 / 0(0 \%)$, pT2 (involvement of lamina muscularis propria) $=0 / 4(0 \%)$, pT3 (involvement of subserosa) $=11 / 23(48 \%)$, pT4a, b (involvement of visceral peritoneum; spreading to adjacent organs $)=2 / 6(33 \%)$. Nodal staging was $\mathrm{pN} 0=7 / 17(41 \%)$, $\mathrm{pN} 1 \mathrm{a}, \mathrm{b}=4 / 10(40 \%), \mathrm{pN} 2 \mathrm{a}, \mathrm{b}=2 / 6(33.6 \%)$.

The primary cell line derived from lymph nodes (to$\mathrm{tal}=14 / 20)$ : pT1 (involvement of mucosa) $=1 / 1(100 \%)$, pT2 (involvement of lamina muscularis propria) $=1 / 3$ $(33 \%)$, pT3 (involvement of subserosa) $=8 / 12(66 \%)$, pT4a, b (involvement of visceral peritoneum, spreading to adjacent organs) $=4 / 4(100 \%)$. Nodal staging [10] was $\mathrm{pN}(0+\mathrm{ITC}+)=4 / 7(57 \%), \mathrm{pN} 1 \mathrm{a}, \mathrm{b}=6 / 8(75 \%), \mathrm{pN} 2 \mathrm{a}, \mathrm{b}$ $=4 / 5(80 \%)$.

The lengths of the passages were recorded. The average time from the sampling until the 1st passage in the cultures from primary tumour sites was 16.9 days, between the $1^{\text {st }}$ and the $2^{\text {nd }}$ passage 7.2 days, and between the $2^{\text {nd }}$ till the $3^{\text {rd }}$ passage 5.38 days. The average time from the sampling until the 1st passage in the cell cultures derived from the metastatic lymph nodes was 18.7 days, between the $1^{\text {st }}$ and the 2 nd passage 5.8 days, and between the $2^{\text {nd }}$ and the $3^{\text {rd }}$ passage 6.7 days.

As part of routine predictive testing, 15 patients, diagnosed for colon cancer and as well for metastasis to lymph nodes were tested for $K R A S$ codon 12, 13, 59, 61, 117 and codon 146 mutations, NRAS codon 12, 13, 59, 61, 117 and 146 mutations, $P T E N$ splice var. and BRAF p.V600E mutations. DNA was isolated from the formalin-fixed paraffin embedded tissue. In our study we found an incidence of $67 \%$ KRAS mutations with the most commonly identified being c.35G>A (p.G12D; 21\%) and c.38G>A (p.G13D; $14 \%)$. Three patients (21\%) were found to have the mutations $B R A F$ c.1799T>A; p.V600E. Only one patient (7\%) tested positive for PTEN mutation c.802-2A $>$ T, splice var. All the tested samples were NRAS wild type (Table 2).

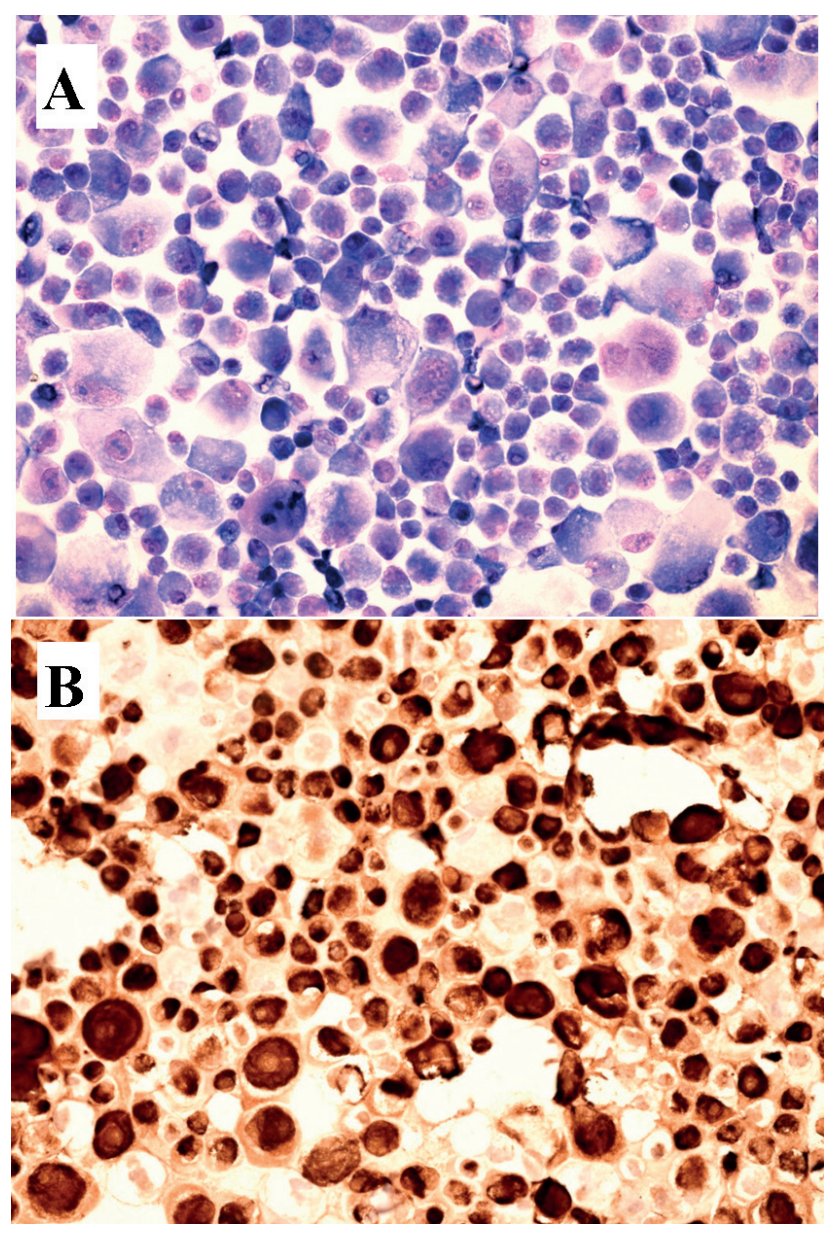

Fig. 2. Primary cell line derived from lymph node metastasis. Cytological features of malignity in this case include anisocytosis, anisokaryosis, increased nuclear-cytoplasmic (N/C) ratio and conspicuous nucleoli (May-Grünwald-Giemsa, 200x, cytospin) (A). Primary cell line derived from lymph node metastasis after second passage. Immunohistochemical stain for cytokeratin shows positivity in most of cultured cells (Cytokeratin AE1/ AE3, 200x, cytospin) (B).

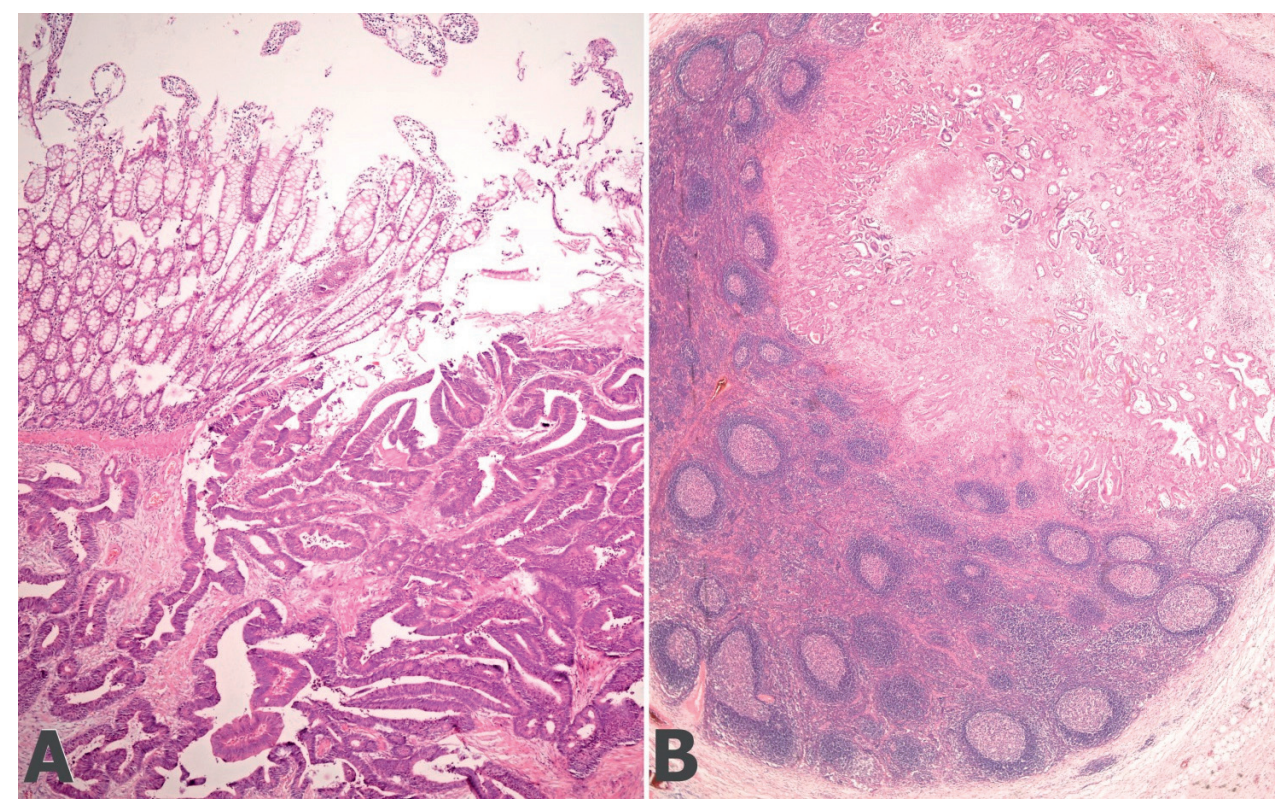

Fig. 3. Border between normal large bowel mucosa (left) and moderately differentiated colorectal carcinoma (right) (40x, H\&E) (A). The lymph node with metastasis of colorectal carcinoma (20x, H\&E) (B). 
Table 3. Molecular characteristics of primary colon cancer and lymph node metastasis according to the percentage of succesful isolation of corresponding cancer cells.

\begin{tabular}{|c|c|c|c|}
\hline Molecular markers & $\begin{array}{l}\text { Total No. of lymph node } \\
\text { metastasis }(n=15)\end{array}$ & $\%$ of isolation primary tumor & $\begin{array}{l}\% \text { of isolation } \\
\text { lymph node }\end{array}$ \\
\hline KRAS mutation & 10 & $4 / 10(40 \%)$ & $6 / 10(60 \%)$ \\
\hline$B R A F$ mutation & 3 & $2 / 3(67 \%)$ & $0 / 3(0 \%)$ \\
\hline PTEN mutation & 1 & $0 / 1(0 \%)$ & $1 / 1(100 \%)$ \\
\hline Wild type & 1 & $0 / 1(0 \%)$ & $1 / 1(100 \%)$ \\
\hline
\end{tabular}
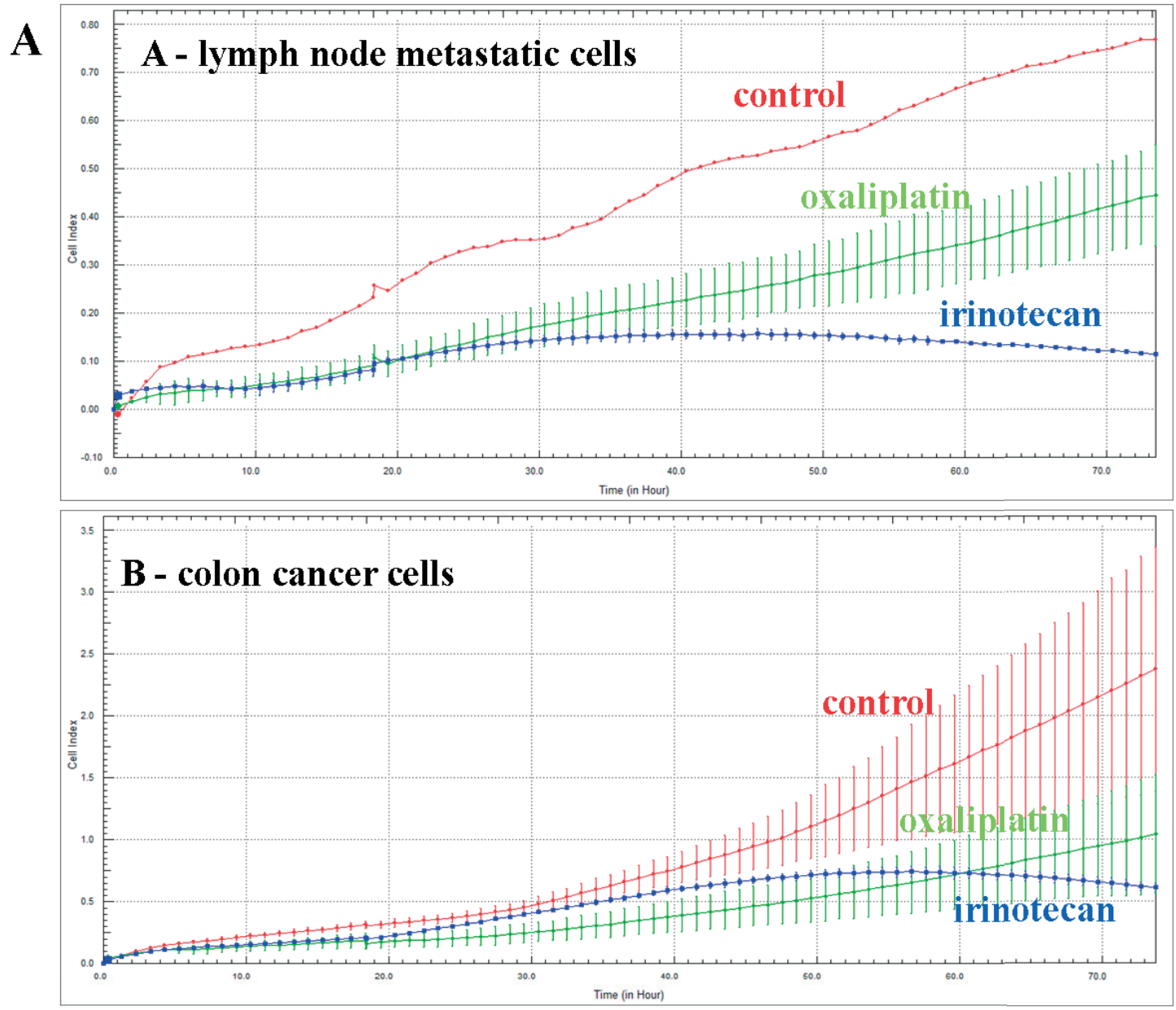

B
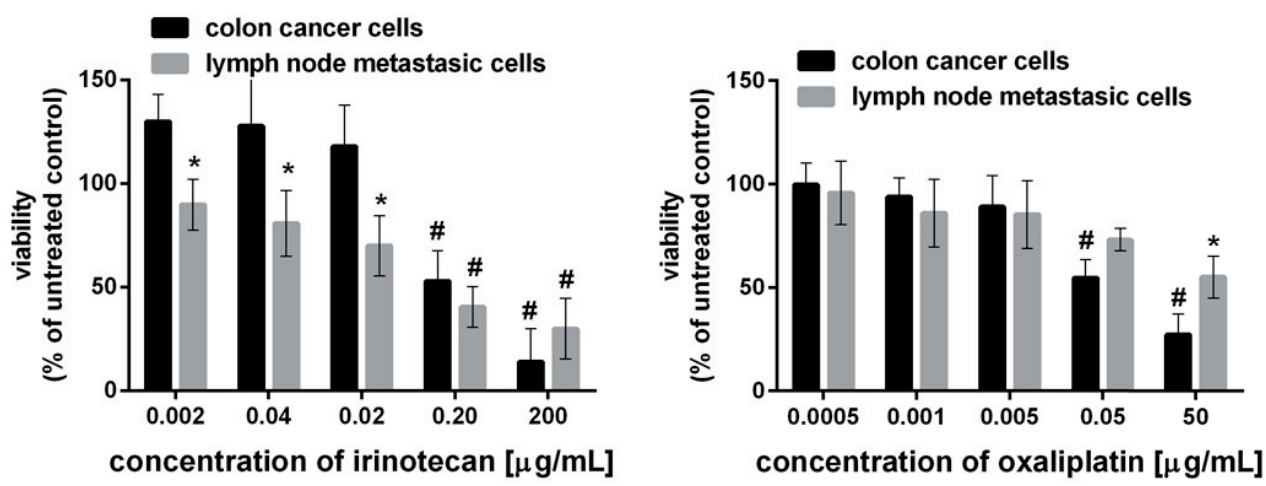

Fig. 4. Cell proliferation test of lymph node metastatic cells and colon cancer cells monitored by the X-CELLigence system (A). Cells were treated with irinotecan and oxaliplatin. Cell index values represent arbitrary units calculated from the relative changes in impedance. The viability (measured using the WST-1 test) (B) after 48h treatment of lymph node metastatic cells and colon cancer cells with irinotecan and oxaliplatin. Results were expressed as percentage of control (=100\%). Data represent the mean \pm SD from two independent experiments. ${ }^{*} P<0.05$ primary colon cancer cells versus respective lymph node metastatic cells; \# $P<0.05$ treated cells versus untreated control. 
Mutational analysis (KRAS, NRAS, BRAF, and PTEN) was undertaken of the primary tumours in patients with metastasis to lymph nodes (15 samples in total, with 2 proving inappropriate for this analysis) with successful establishment of primary cell lines as follow (Table 3):

One primary cell line from the primary tumours (total=6/15): $K R A S$ mutation $=4 / 10(40 \%), B R A F$ mutation $=2 / 3(67 \%)$.

One primary cell line derived from the lymph nodes (total=8/15): KRAS mutation $=6 / 10(60 \%), B R A F$ mutation $=0 / 3(0 \%)$, PTEN mutation $=1 / 1(100 \%)$ and wild type $=1 / 1(100 \%)$.

The colon cancer cell line and the metastatic lymph node cancer cell line were treated with different concentrations of irinotecan and oxaliplatin. After $48 \mathrm{~h}$ incubation, metabolic activity of the cells was measured using a WST-1 test. Simultaneously, a comparison of proliferation ability was performed using real time analysis (X-CELLigence system). The viability of the cells treated with irinotecan and oxaliplatin was monitored in real time, each $1 \mathrm{~h}$ for $72 \mathrm{~h}$. A fixed concentration of chemotherapeutics (irinotecan $0.2 \mu \mathrm{g} / \mathrm{mL}$; oxaliplatin $50 \mu \mathrm{g} / \mathrm{mL}$ ) were used and compared with untreated cells. A higher proliferation potential was recorded in the colon cancer cells (cell index 2.5 after $72 \mathrm{~h}$ ) in comparison with the lymph node metastatic cells. The more pronounced effect on metabolic activity, as well as increased proliferation of the cells was observed after irinotecan treatment in both types of cells, especially after treatments at higher concentrations.

\section{DISCUSSION}

The establishment of cell cultures using neoplastic cells from human tumours is a relatively routine procedure, although multiple methods are used ${ }^{8}$. Several successful isolations of enterocytes have been described, using various procedures ${ }^{9-11}$. Most of these methods, such as separation using magnetic nano-beads, or separation on the specific density gradient ${ }^{11}$ allows only for the isolation of specific cells types. It has become increasingly evident, however, that tumour stroma has an essential role in invasion and may have a promoting effect on tumor progression as well. Thus, for assays with physiological relevance, stromal components such as fibroblasts, endothelial cells etc. should be incorporated into the experiments ${ }^{8}$.

The isolation of cells from contaminated tissue such as from the colon is quite difficult, but it is an unavoidable problem, that must be overcome. Glaysher et al described the isolation of colon cancer cells by enzymatic dissociation in the presence of relatively high concentration of antibiotics with $80-90 \%$ success rate ${ }^{4}$. In comparison with our experiments, only $39 \%$ primary cancer cells were obtained from primary colon tumors. The major limitation was probably due to higher microbial contamination of the cell cultures with intestinal content, in spite of using antibiotics and antifungal agents. Higher doses of antibiotics or antimycotics could solve this problem. However, antibiotic treatment might have interfered with drug test- ing, and the overuse of antibiotics leads to the selection of resistant organisms in cell cultures, just as it does in the population at large ${ }^{8}$.

Four basic methods of tumour dissociation have been described in the literature. The first consists of mechanical dissociation of the tissue by mincing with a knife, scissors or other bladed instruments, and then meshing, filtration and separation on a specific density gradient. This easy and effective technique represents a comparatively easy way to prepare the cell suspension, although it exposes the cells to relatively high mechanical stress that may lead to cell death ${ }^{3,6}$. The second method uses sequestration of the extracellular matrix bonds after exposure to chelating agents such as EDTA or EGTA. Enzymes such as trypsin, collagenase, hyaluronidase or elastase can be also used ${ }^{12,13}$. The third possible way is the separation using magnetic nano-beads, particles coated with different adhesion molecules (e.g. EpCAM) or antibodies that allow selective separation of required cell populations. Magnetic beads are also supplied in ready-to-use kits 9 Nevertheless, the isolation of cells by nano-beads selects a narrow cell population and suppresses other heterogenic population of cells inside the tumour. The fourth method involves the planting of small pieces of the tissue in the cultivation media with an amount of foetal bovine serum. Even larger pieces of tissue can be used, although the supply of oxygen and other nutrients inside the tissue may be impaired. Natural architecture and intercellular signalization among cells is well preserved for a couple of passages, but this method is not appropriate for long term cultivation.

In comparison with the above described methods, our approach retains the original features of the cells, as mechanical and enzymatic stress is minimized. It also preserves all cell types from tumours and the cells of surrounding stroma, thus enabling effective derivation from both colorectal cancer primary and its metastases. Based on this method, stromal components were maintained, enabling preservation of cancer cells microenvironment and thus supporting cellular growth and proliferation in contrast with selected cell line.

Lymph node status is one of the most important prognostic factors for colorectal carcinoma. Tumour cells invade the lymphatic vessels, enabling tumour cells to penetrate into the lymphatic system. Both experimental and pathological/clinical data indicate that the growth of lymphatic vessels close to solid tumours is often associated with lymph node metastasis ${ }^{14,15}$. In our study, the site of primary tumour sampling was selected by a pathologist, who sampled the specimen in order to preserve crucial features (i.e. resection margins, areas of the deepest tumour invasion). Areas of necrosis were avoided. Lymph nodes with potential metastatic involvement were chosen by size and tactile properties, despite the fact that metastatic involvement is not always the cause of lymph node enlargement, since the nodes can acquire the same macroscopic appearance in case of immunological activation or node necrosis. Even a histological examination assuming no metastatic involvement is limited by the thickness $(5 \mu \mathrm{m})$ of the cuts. A relatively higher rate of success 
(18.4\%) was observed when the largest node obtained was the only positive node in the tumour.

The data from our genetic studies show similar incidence of mutations in $K R A S, B R A F$ and $P T E N$ as descibed in literature, with slightly higher incidence of $K R A S \mathrm{mu}-$ tations ( $53 \%$ of tested sample). This suggests that $K R A S$ mutated status facilitates growth of cancer cells in culture; the data, however, were not statistically significant nut this may reflect small size of our testing sample. No features (i.e. average time tills the $1^{\text {st }}$ passage) were observed in the cell cultures that might correlate with mutational status.

In the future, parallel testing of mutations, genetic signatures and sensitivity on chemotherapy or targeted therapy will likely be done routinely for every patient. There is a pressing need for a technology that would expeditiously generate ultra-low passage cancer cell lines which produce large quantities of cells for multiple clinical tests ${ }^{16}$. In our study, the interval between passages shortened with increased proliferation of the cells in the culture. The short prolongation of time from $2^{\text {nd }}$ to $3^{\text {rd }}$ passage was probably due to the usage of larger cultivation flasks. Generally, the growth of the cells derived from the primary tumours was faster. The reason could be the higher proportion of cancer cells in the sample at the beginning of cultivation as compared to the lymph nodes samples and the supportive effect of the tumour stroma in cultures.

Colon cancer cells and cells from respective lymph node metastases from a single patient provide a unique model appropriate for the study of tumour progression and other metastatic features. The morphology and phenotypic differences of both types of isolated cells could be said to recapitulate the features of immortalized cell line models SW480 and SW620, since they are derived from primary and secondary tumours resected from a single patient as well. SW480 cells (colon cancer cell line) have an epithelial-type morphology in the formation of cohesive groups, while SW620 cells (lymph node metastatic cell line) have a rounded or spindle-shaped fibroblast-like morphology ${ }^{17}$ and are less cohesive, like those in our tested cell lines. On the other hand, a higher proliferation was found in the SW620 cells than in the SW480 cells ${ }^{17}$, while proliferation index of newly isolated cell lines was more greatly increased in colon cancer cells as compared to respective lymph node cancer cells. Our previous study provided a comparison of the described isolated cell lines and immortalized cell lines, colon cancer cells SW480 along with respective lymph node metastatic cells SW620. Many similarities as well as several differences have been demonstrated, stemming probably from the selection of aggressive clones during passaging together with the important role of stromal support in isolated cell lines ${ }^{18}$.

Historically, stable cancer cell lines have proved valuable in all fields of cancer research. Primary cell lines have at least the same potential, especially with increasing efforts for individualization of cancer therapy.

\section{CONCLUSION}

In summary, using a simple but effective method the mechanical dissociation of tissue - we derived and established 13 primary colorectal cell lines from primary tumours with an effectiveness of $39.4 \%$, as well as 14 cell lines derived from respective lymph node metastases with an effectiveness at $70 \%$. The most efficient isolation and cultivation of cancer cells from lymph nodes was observed in specimens at a higher stage of primary tumour and lymph node involvement, as well as in tumours with histological presence of angioinvasion and perineural spreading. In addition, the determination of proliferation and sensitivity to cytostatic treatment has demonstrated the functionality of this model. A sufficient amount of suitable material for immuno-pathological evaluation, cytotoxicity and proliferation testing as well as in vivo experiments was obtained. A more detailed characterization will be discussed in further studies.

Acknowledgement: The authors would like to thank Svetlana Kopecka for her laboratory support in preparation of the cell lines. This work was supported by the Czech Ministry of Health [project IGA No. NT141503/2013], by the Charles University in Prague [program PROGRES Q40/01 and PROGRES Q40/11], by the project BBMRI-CZ LM2015089 and by the project CZ .02.1.01/0.0/0.0/16_013/0001674. We thank Daniel Paul Sampey, MFA, for the corrections of English language.

Author contributions: VH: design of experiments; LK, JS: isolation of the primary cells and performance of immunocytochemistry and immunohistochemistry techniques; SJ: performance of experiments with cancer cells; VH, LK, SJ: data analysis; VH, LK: 1st draft of paper; JS, SJ: revision of paper.

Conflict of interest statement: The authors state that there are no conflicts of interest regarding the publication of this article.

\section{REFERENCES}

1. Ferlay J, Soerjomataram I, Dikshit R, Eser S, Mathers C, Rebelo M, Parkin DM, Forman D, Bray F. Cancer incidence and mortality worldwide: Sources, methods and major patterns in GLOBOCAN 2012. Int J Cancer 2015;136(5):E359-86. doi:10.1002/ijc.29210.

2. ČR Úzis. Národní onkologický registr. Available from URL: Available from: http://www.uzis.cz/registry-nzis/nor.

3. Mitra A, Mishra L, Li S. Technologies for deriving primary tumor cells for use in personalized cancer therapy. Trends Biotechnol 2013;31:347-54.

4. Glaysher S, Cree IA. Isolation and culture of colon cancer cells and cell lines. Methods Mol Biol 2011;731:135-40.

5. Mitaka T. The current status of primary hepatocyte culture. Int J Exp Pathol 1998;79:393-409.

6. Ljung BM, Mayall B, Lottich C, Boyer C, Sylvester SS, Leight GS, Siegler HF, Smith HS. Cell dissociation techniques in human breast cancer-variations in tumor cell viability and DNA ploidy. Breast Cancer Res Treat 1989;13:153-9.

7. TNM Clasification of Malignant Tumours. In: LHS, MK G, CW, editors: Wiley-Blackwell, 2009:336.

8. Cree IA. Cancer Cell Culture: Methods and Protocols. 2nd ed, 2011.

9. Chougule P, Herlenius G, Hernandez NM, Patil PB, Xu B, SumitranHolgersson $\mathrm{S}$. Isolation and characterization of human primary 
enterocytes from small intestine using a novel method. Scand J Gastroenterol 2012;47:1334-43.

10. Loret S, Rusu D, El Moualij B, Taminiau B, Heinen E, Dandrifosse G, Mainil J. Preliminary characterization of jejunocyte and colonocyte cell lines isolated by enzymatic digestion from adult and young cattle. Res Vet Sci 2009;87:123-32.

11. Rusu D, Loret S, Peulen O, Mainil J, Dandrifosse G. Immunochemical, biomolecular and biochemical characterization of bovine epithelial intestinal primocultures. BMC Cell Biol 2005;6:42.

12. Cunningham RE. Tissue disaggregation. Methods Mol Biol 2010;588:327-330.

13. Li WC, Ralphs KL, Tosh D. Isolation and culture of adult mouse hepatocytes. Methods Mol Biol 2010;633:185-96.

14. Achen MG, Stacker SA. Molecular control of lymphatic metastasis. Ann N Y Acad Sci 2008;1131:225-34.
15. Royston D, Jackson DG. Mechanisms of lymphatic metastasis in human colorectal adenocarcinoma. J Pathol 2009;217:608-19.

16. Ray S, Langan RC, Mullinax JE, Koizumi T, Xin HW, Wiegand GW, Anderson AJ, Stojadinovic A, Thorgeirsson S, Rudloff U, Avital I. Establishment of human ultra-low passage colorectal cancer cell lines using spheroids from fresh surgical specimens suitable for in vitro and in vivo studies. J Cancer 2012;3:196-206.

17. Hewitt RE, McMarlin A, Kleiner D, Wersto R, Martin P, Tsokos M, Stamp GW, Stetler-Stevenson WG. Validation of a model of colon cancer progression. J Pathol 2000;192:446-454.

18. Krbal L, Hanusova V, Soukup J, John S, Matouskova P, Ryska A. Contribution of in vitro comparison of colorectal carcinoma cells from primary and metastatic lesions to elucidation of mechanisms of tumor progression and response to anticancer therapy. Tumour Biol 2016;37:9565-78. 